\title{
Verification of the spar model of a reinforced concrete beam
}

\author{
Oleg Mkrtychev ${ }^{1}$, Marina Busalova ${ }^{1 *}$, and Vladimir Dorozhinskiy ${ }^{2}$ \\ ${ }^{1}$ Moscow state university of civil engineering, Yaroslavskoye shosse, 26, Moscow, Russia, 129337
}

\begin{abstract}
The paper presents the outcomes of the research aimed at the verification of the computational model simulating a reinforced concrete beam employing spar and 3D finite elements, with account taken of physical nonlinearity. Structural calculations involved in R\&D and design effort must factor in non-linear structural behavior both of the material and of structural elements. In particular, this is valid for the analysis of special types of impact (seismic, accidental etc.). However, design models under development may incorporate significantly varying models of nonlinear materials as well as different kinds of finite elements, and both have to be verified. This article considers two models of a hinged (pinned) beam. In the first case, the modeling was based on 3D elements for concrete and on spar elements for reinforcement using Euler-Lagrange coupling of finite elements belonging to concrete and reinforcement (three-dimensional model). The second case the simulation based on spar finite elements (spar model). Both the spar model and 3D model allow for non-linear nature of concrete and reinforcement. In case of concrete the material was set using the Continuous Surface Cap Model, while the reinforcement was modeled involving a bilinear diagram of material behavior.
\end{abstract}

\section{Problem setting}

Design calculations of buildings and structures performed to take account of a particular case or type of impact require that the non-linear nature of structures' and materials' behavior be factored in. The present research presents a verification of a reinforced concrete beam. Two models of a hinged (pinned) beam were devised during the research: a three-dimensional model consisting of $3 \mathrm{D}$ elements with concrete and reinforcement coupled, and a spar model (Figure 1).

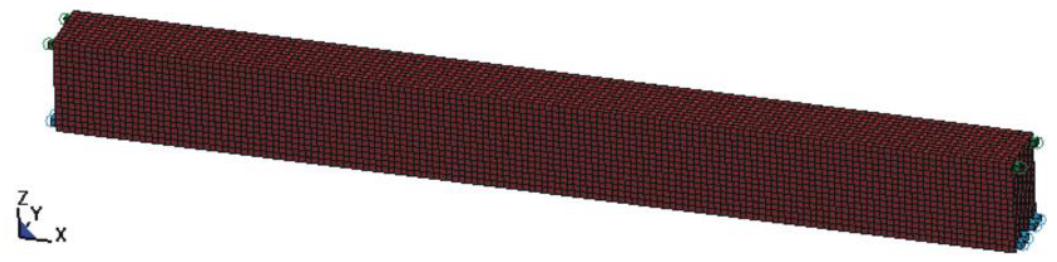

*Corresponding author: marina8busalova@gmail.com 
Fig. 1. Model of a beam.

Beam material is B25, span $6 \mathrm{~m}$, section $400 \times 600(\mathrm{~h}) \mathrm{mm}$. The 3D model made use of the concrete non-linear material CSCM (Continuous Surface Cap Model), developed at the U.S. Department of Transportation, Federal Highway Administration [1]. Figure 2 presents the yield surface of primary stresses in space in accordance with this model of concrete [2].
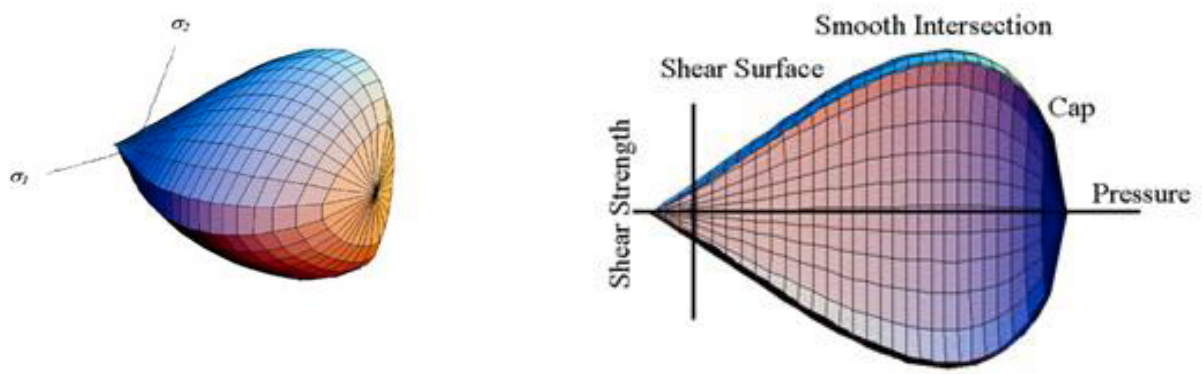

Fig. 2. The mathematical model of concrete (CSCM - Continuous Surface Cap Model).

The yield surface for this model is expressed in terms of stress invariants:

$$
J_{1}=3 P, J_{2}^{\prime}=\frac{S_{i j} S_{i j}}{2}, J_{3}^{\prime}=\frac{S_{i j} S_{i k} S_{k i}}{3}
$$

where $J_{1}$ stands for the first invariant of the stress tensor, $J_{2}^{\prime}$ - second invariant of the stress deviator, $J_{3}^{\prime}$ - third invariant of the stress deviator, $S_{i j}$ - stress deviator, $P$ - pressure.

The CSCM concrete model allows modeling structural elements via 3D finite elements and taking account of the actual reinforcement of a structure (Figure 3), which constitutes an important factor when investigating the behavior of buildings and structures exposed to accidental and seismic impact $[3,4]$. Reinforcement for this A500C class beam was selected based on a static calculation of load encompassing the own gravity load and a $30 \mathrm{kN} / \mathrm{m}$ load distributed along the length of the beam. Based on the static calculation presuming crack resistance, the beam was reinforced in the lower area with four $20 \mathrm{~mm}$ rods, in the upper area with two $18 \mathrm{~mm}$ rods and $10 \mathrm{~mm}$ stirrups with $100 \mathrm{~mm}$ pitch at the bearing and 300 $\mathrm{mm}$ in the span.

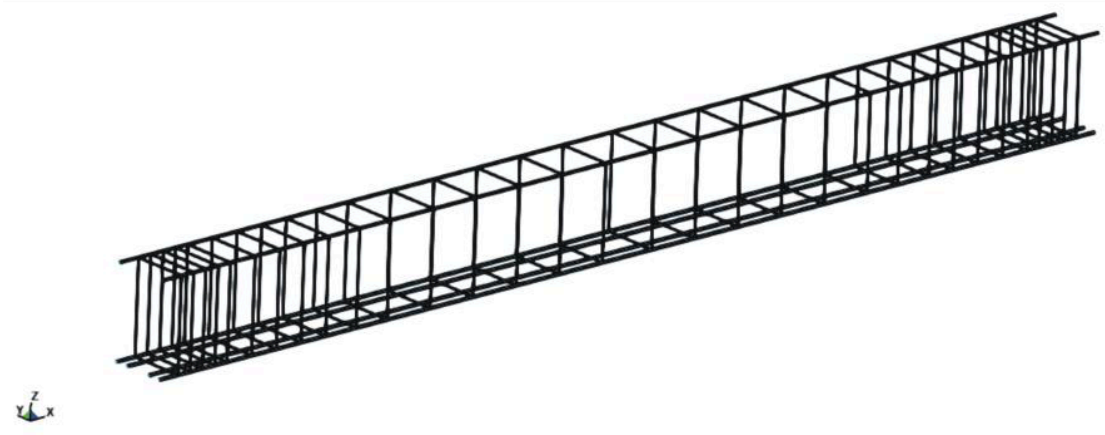

Fig. 3. 3D model of the beam's reinforcement cage.

The beam modeled with spar finite elements had the behavior of its material set via a bilinear diagram (Figure 4). 


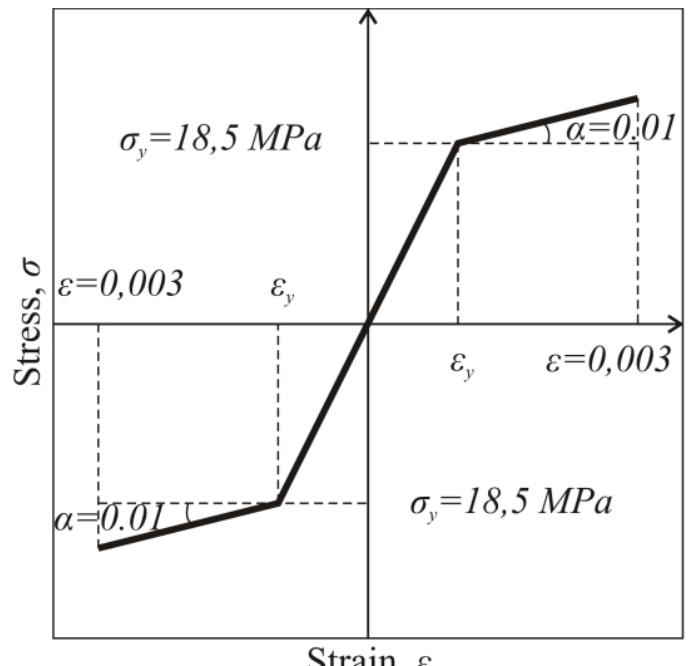

Fig. 4. Elastoplastic model of concrete.

The yield function for the diagram presented in Figure 4 is determined from the expression:

$$
\phi=\frac{s_{i j} s_{i j}}{2}-\frac{\sigma_{y}^{2}}{3} \leq 0
$$

where

$$
\sigma_{y}=\beta\left[\sigma_{0}+f_{k}\left(\varepsilon_{e f f}^{p}\right)\right] .
$$

$f_{k}\left(\varepsilon_{\text {eff }}^{p}\right)$ denotes the hardening function, $\beta$ - speed of deformation.

Assuming the beam to be an isotropic rod is the most widely used approach utilized when developing computational models. However, this particular case considers the transformed cross section of the beam, with the reinforcement taken as integral and seen as evenly distributed across the section. Besides, the so-called reduced modulus of elasticity is introduced.

The calculations were performed in a nonlinear static setting. In case the finite element of the spar model (beam) reached the value of 0,003 , the element was considered collapsed and was eliminated from the structural behavior. The failure of the three-dimensional beam is represented by the plastic deformation in the longitudinal effective reinforcement hitting the value of 0,05 .

The numerical study has the following progression: the beams are exposed to their own gravity load and to a gradually increasing load distributed along the length. The load of failure is registered. The stress limits for concrete and reinforcement are considered equal to guideline values.

\section{Findings of the research}

Figures 5-7 demonstrate the isofields of intensity of plastic deformations in the concrete of the three-dimensional beam exposed to various loads. 


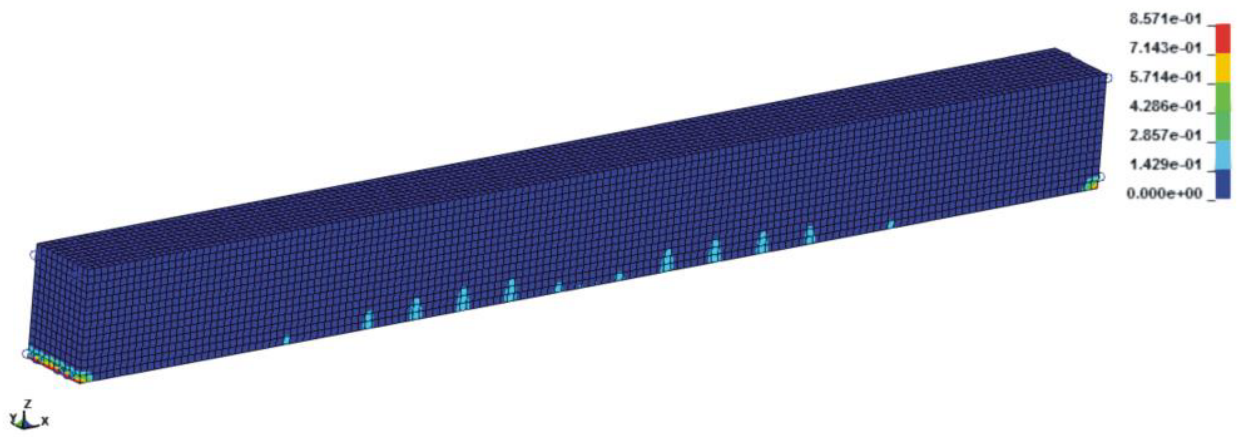

Fig. 5. Intensity isofields of plastic deformations in the beam. Commencement of crack opening. Load $32 \mathrm{kN} / \mathrm{m}$.

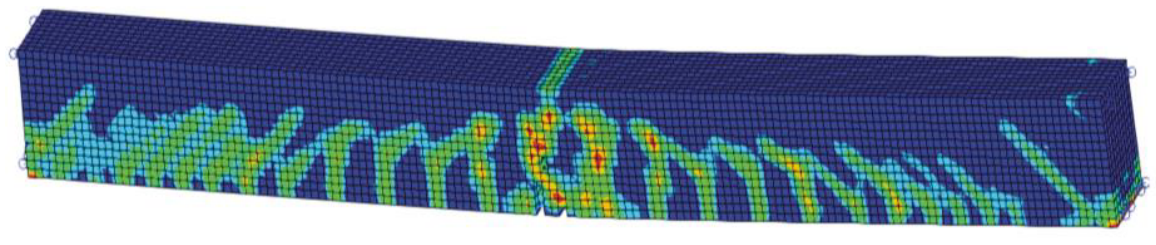

$i^{2} x$

Fig. 6. Intensity isofields of plastic deformations in the three-dimensional beam. Plastic deformations intensifying in the upper layers of the section in the middle of the span, cracks opening in the lower layers of the section. Load $171 \mathrm{kN} / \mathrm{m}$.

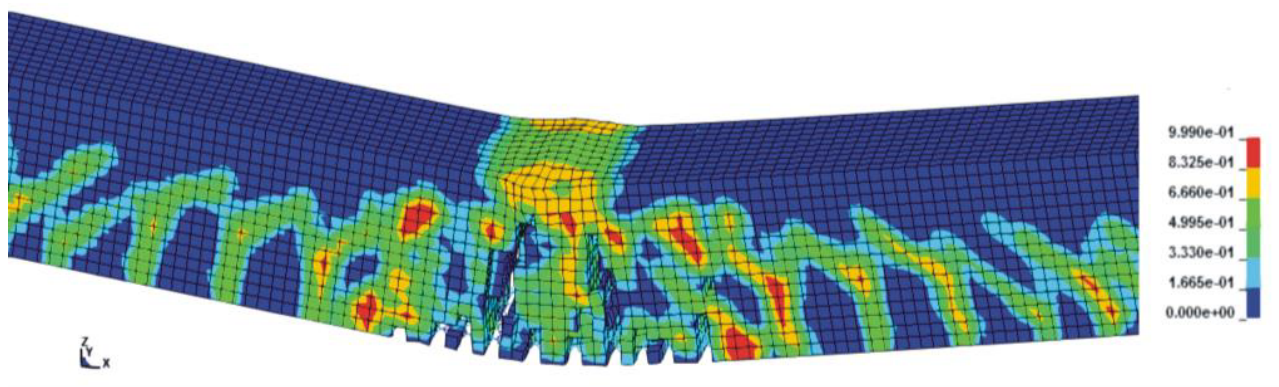

Fig. 7. Intensity isofields of plastic deformations in the concrete of the beam. The beam collapsing. Load $191 \mathrm{kN} / \mathrm{m}$.

Figures 8-10 display the intensity isofields of plastic deformations in the reinforcement cage of the three-dimensional beam, taking place at different times under various loads.

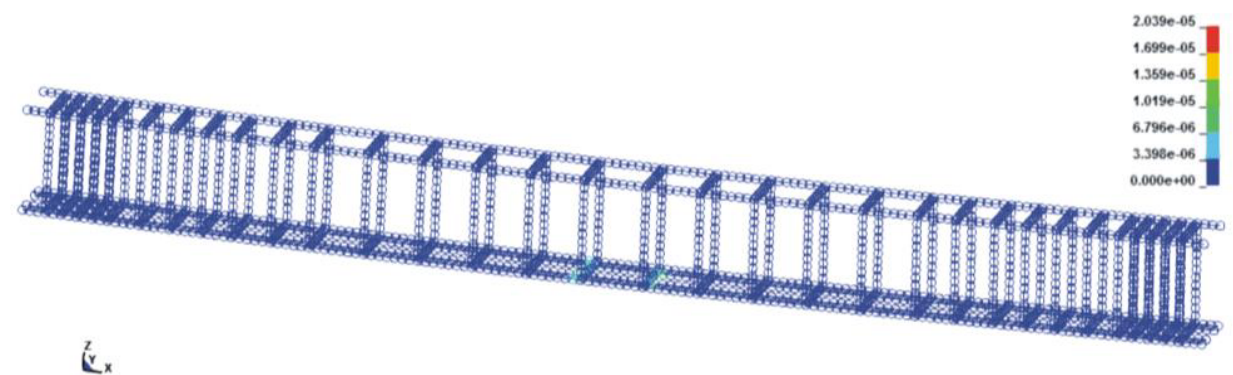


Fig. 8. Intensity isofields of plastic deformations in the reinforcement cage. Plastic deformations emerging in the lower working reinforcement. Load being $141 \mathrm{kN} / \mathrm{m}$.

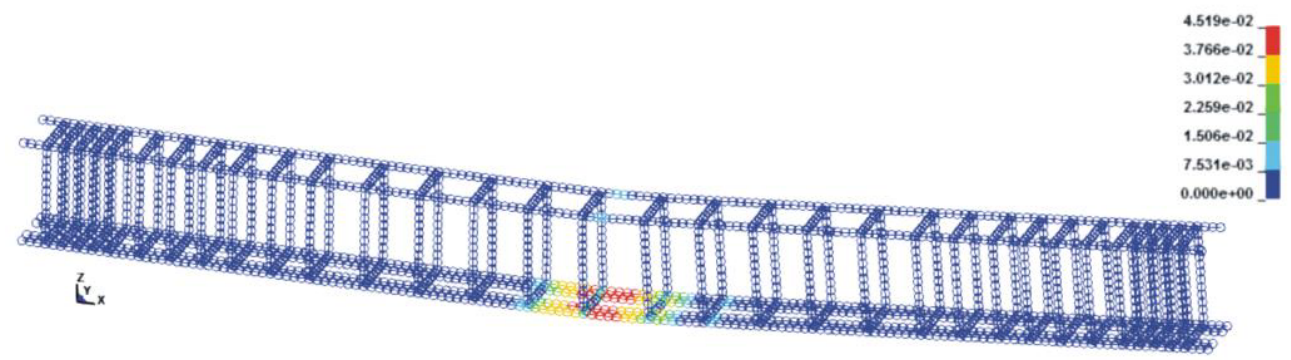

Fig. 9. Intensity isofields of plastic deformations in the reinforcement cage. Plastic deformations emerging in the lower working reinforcement. Load being $177 \mathrm{kN} / \mathrm{m}$.

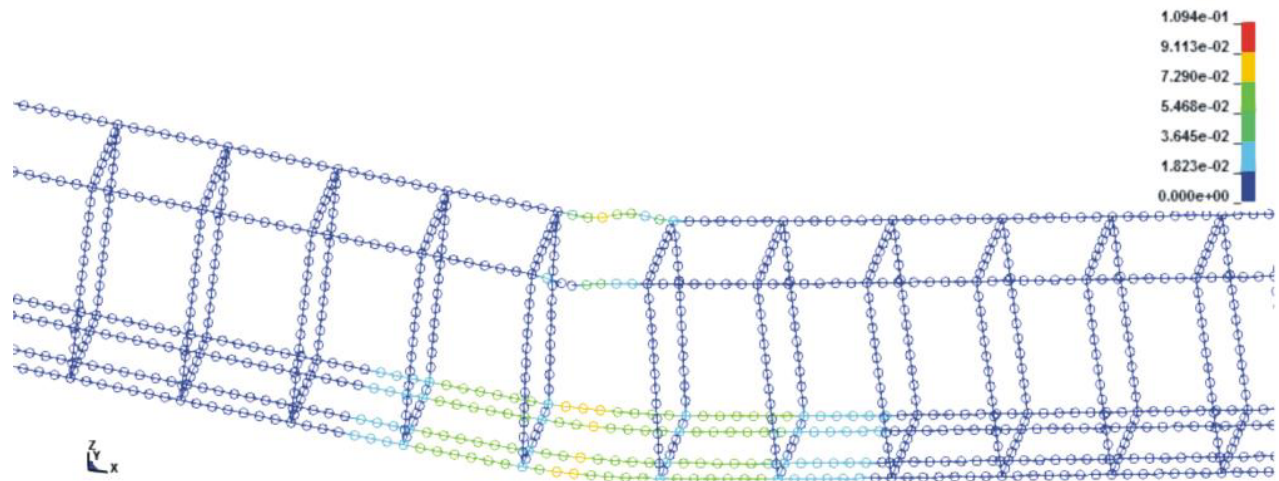

Fig. 10. Intensity isofields of plastic deformations in the reinforcement cage. Upper working reinforcement being compressed and losing stability, the beam collapsing. Load being $191 \mathrm{kN} / \mathrm{m}$.

Figures 11-12 display isofields of intensity of plastic deformations in the beam modeled via spar elements, at different times under various loads.

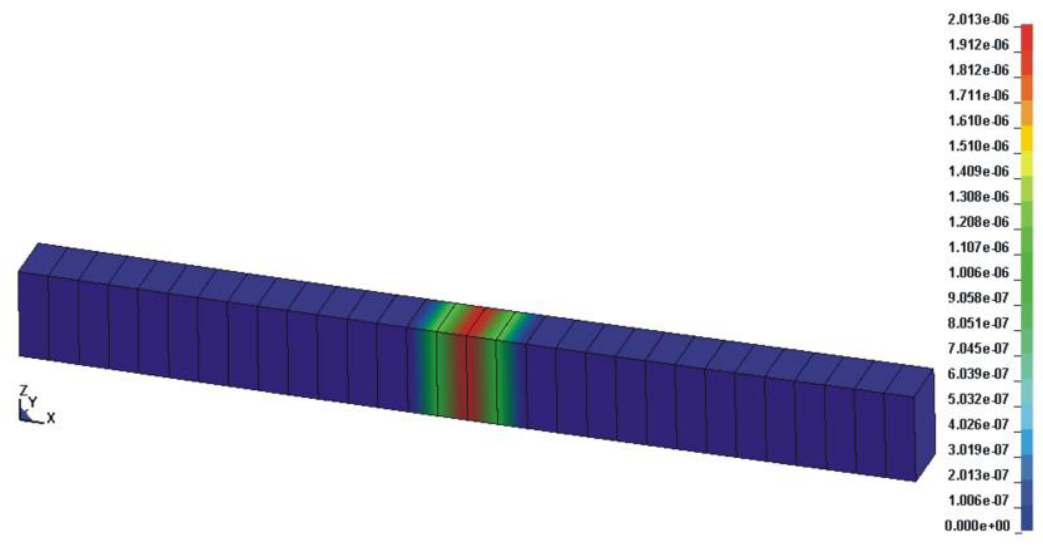

Fig. 11. Intensity isofields of plastic deformations in a beam modeled as a spar. Plastic deformations emerging. Load being $121 \mathrm{kN} / \mathrm{m}$. 


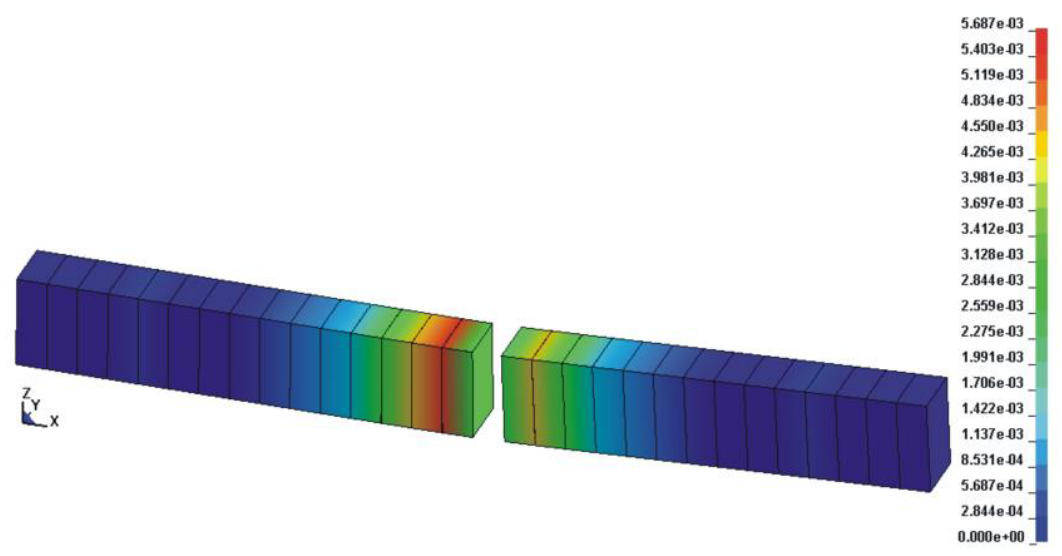

Fig. 12. Intensity isofields of plastic deformations in a rod model of a beam. Beam collapsing in the middle of the span. Load being $165 \mathrm{kN} / \mathrm{m}$.

Table 1 presents the values of destructive load causing beams modeled in different ways to collapse.

Table 1. Destructive load values and collapse time for beams.

\begin{tabular}{|c|c|}
\hline & $\begin{array}{c}\text { Load distributed } \\
\text { along the length, } \\
\mathbf{k N} / \mathbf{m}\end{array}$ \\
\hline Beam modeled with spar elements & 165 \\
\hline $\begin{array}{c}\text { Beam modeled with 3D elements and rod- } \\
\text { type reinforcement. Diameter of lower } \\
\text { working reinforcement 20 mm }\end{array}$ & 191 \\
\hline $\begin{array}{c}\text { Beam modeled via 3D elements and rod- } \\
\text { type reinforcement. Diameter of the lower } \\
\text { working reinforcement } 18 \mathrm{~mm}\end{array}$ & 165 \\
\hline
\end{tabular}

Thus, the verification of the reinforced concrete beam enables us to draw the following conclusions:

1. Mathematical models of beams comprised of spar elements are acceptabe for use in calculations in case the loads are nearly destructive and non-linear behavior of materials is accounted for;

2. If used, a mathematical model of beams comprised of spar elements made of a homogenous isotropic material reqiures that an assumption about 'optimal reinforcement' be introduced, meaning that the compressed area of concrete and the stretched working reinforcement collapse in their section simultaneously.

\section{Acknowledgements.}

This study was performed with the financial support of the RF Ministry of Education and Science, grant \#7.1524.2017/Project Part.

\section{References}

1. US Department of Transportation. Federal Highway Administration. Evaluation of LSDYNA Concrete. Material Model 159. FHWA-HRT-05-063, 190 (2007) 
2. Y.D. Murray, Users Manual for LS-DYNA Concrete Material Model 159, FHWAHRT-05-062 (2007)

3. O. V. Mkrtychev, M. S. Busalova, Proc.Eng., 153, 475 (2016)

4. O. V. Mkrtychev, M. S. Busalova, Adv. in Eng, Res., 104, 160 (2016) 